\title{
ŽIVLJENJSKA RAVEN PREBIVALSTVA SLOVENSKEGA OBMEJNEGA OBMOČJA OB MEJI S HRVAŠKO
}

\author{
Dr. Marko Krevs*
}

\section{Izvleček}

Predstavljene so razlike med območii na slovenski strani meje s Hrvaško z vidika živlienjskih razmer prebivalstva. Predstavitev temelji na kompleksnem pristopu $k$ merjenju življenjske ravni tamkajšnjega prebivalstva. Izpostavljena so območja z izrazito ugodnimi oziroma neugodnimi življenjskimi razmerami, ter vidiki živlienjske ravni, s katerih se obravnavana območja najboli razlikujejo.

Klučne besede: slovensko-hrvaško obmejno območje, življenjske razmere prebivalstva, življenjska raven prebivalstva, razlike med območji.

\section{LEVEL OF LIVING OF THE POPULATION ON THE SLOVENIAN SIDE OF THE BORDER WITH CROATIA}

\begin{abstract}
Differences in living conditions of the population between areas on the Slovenian side of the border with Croatia are presented, based on a complex approach to measuring of the level of living. Areas with distinctly favourable or unfavourable living conditions are pointed out, as well as the aspects of level of living that discriminate the most between the studied areas.
\end{abstract}

Key words: Slovenian-Croatian border region, living conditions of the population, level of living, differences between areas.

"Dr., doc., Oddelek za geografiijo, Filozofska fakulteta, Aškerčeva 2, 1000 Liubljana, Slovenija 


\section{Uvod}

Obmejno območje med Slovenijo in Hrvaško je fizičnogeografsko in družbenogeografsko zelo raznoliko. To pomeni, da prebivalstvo različnih obmejnih območij živi v zelo različnih življenjskih razmerah.

$\checkmark$ prispevku se lotimo kompleksne predstavitve življenjskih razmer prebivalstva obravnavanega obmejnega območja. Enostransko predstavljanje tamkajšnjih življenjskih razmer, na primer z vidika prebivalstvenih, gospodarskih ali reliefnih razmer, nas lahko zavede k pretiranemu poenostavljanju. $\mathrm{Na}$ podlagi enostranske predstavitve življenjskih razmer prebivalstva pa lahko tudi pretirano poenostavljeno, ali celo napačno predvidevamo nadaljnje socialnogeografske procese ali ocenjujemo možnosti družbeno-gospodarskega razvoja posameznih območij. Življenjske razmere na primer niso enako (ne)ugodne na območjih s podobno starostno sestavo prebivalstva, če so ta območja različno oddaljena od večjih središčnih naselij, ležijo $v$ reliefno in podnebno izrazito različnih pokrajinah, z različno stopnjo onesnaženosti zraka in pitne vode, stopnja izobrazbe prebivalstva nekaterih območij pa je znatno višja, kot stopnja izobrazbe prebivalstva drugih območij. V prispevku želimo številne vidike življenjskih razmer prebivalstva združiti v skupno informacijo za posamezno (nekdanjo) krajevno skupnost na obmejnem območju. Večina uporablienih podatkov (Analiza, 1996, Cegnar, 1996, DMR, 1992, Integrated, 1995, Krevs, 1998c, Meje, 1994, Podatki, 1993, Popis, 1981, 1991, Popit, 1995, Poslovni, 1996, Špes, 1995, Turistične, 1996) se nanaša na prvo polovico 1990. let.

Za takšno kompleksno, zgoščeno predstavitev razlik v življenjskih razmerah med obmejnimi območji je primerna metoda proučevanja življenjske ravni prebivalstva. Slednjo povzemamo po geografski raziskavi življenjske ravni prebivalstva v Sloveniii (Krevs 1998a).

Žal se $v$ prispevku zaradi dostopnosti podatkov in opravljenih raziskav (Krevs 1996, 1998 a,b,c, 1999) omejujemo le na slovensko stran obmejnih območij med Slovenijo in Hrvaško. 


\section{Opredelitev obmejnega območja}

Obmejna lega je lahko $v$ strokovni in poljudni literaturi ter vsakdanjem življenju opredeljena in ovrednotena na zelo različne načine. "Tradicionalne" so na primer miselne povezave obmejnosti s perifernostjo, oddaljenostjo od središča (države), demografsko ogroženostjo ali gospodarsko zaostalostjo. Nasprotne, z ugodnim prizvokom, so povezave obmejnosti z možnostmi prekomejnih gospodarskih, kulturnih, osebnih stikov in povezav. Z globalizacijskimi procesi naj bi državne meje vse boli izgubljale svoj tradicionalni pomen in večinoma postale "neopazne".

Navedene izjave govorijo o obmejnem prostoru kot prepoznavni entiteti. $\checkmark$ resničnosti ta entiteta ni tako enolično prepoznavna, saj njenega obsega ni preprosto opredeliti. Če obmejnost opredelimo na podlagi "še opaznega vpliva bližine (meddržavne) meje", lahko pridemo do obmejnega območja zelo različnega obsega. Kot obmejno lahko prepoznamo kar celotno ozemlje Slovenije, ali pa le ozek obmejni pas, na primer območje intenzivnejše dnevne migracije ali t.i. dvolastništva (lastništva nepremičnin na obeh straneh meje). Ker so opredelitve obmejnega območja lahko tako zelo različne, so lahko že zgolj zaradi tega tudi spoznanja o obmejnih območjih zelo različna. Zato je v tovrstnih raziskavah pomembno, da natančno opredelimo, katera območja pojmujemo kot obmejna.

$\checkmark$ našem primeru smo se odločili za opredelitev obmejnega območja na podlagi (nekdanjih) krajevnih skupnosti, katerih pretežni del poseljenih površin je $v$ desetkilometrskem obmejnem pasu.

\section{Življenjska raven prebivalstva}

Življenjska raven je čimboli celovita informacija o življenjskih razmerah prebivalstva $v$ določenem časovnem obdobju na določenem območju, oziroma o pogojih za zadovoljevanje njihovih življenjskih potreb (Krevs, $1998 a, 18)$. Pristopi k merjenju življenjske ravni se močno razlikujejo. Vzroki za to so zlasti velike razlike $v$ njenem pojmovanju, različna prostorska merila proučevanja, različna dostopnost ustreznih podatkov in različni pristopi raziskovalcev. $\vee$ že omenjeni raziskavi življenjske ravni (ibid.), katere podatke uporabimo tudi $v$ tem prispevku, smo sledili kompleksnim pojmovanjem in 
merjenjem življenjske ravni (na primer Drewnowski, Scott, 1966, Knox, 1975, Okrogla miza, 1991, Vuics, 1994, Novak, 1996), ki smo jih izpopolnili zlasti z ustreznejšim upoštevanjem (prostorske) dostopnosti lokacii, kjer obstajajo možnosti za zadovoljevanje določenih življenjskih potreb prebivalstva ter z upoštevanjem nekaterih fizičnogeografskih značilnosti in onesnaženosti okolja, $\checkmark$ katerem živi prebivalstvo. Vidiki, s katerih smo proučili življenjsko raven prebivalstva, so naslednji: premoženje in dohodki prebivalstva, premoženje kmečkih gospodarstev, stanovanjske razmere, značilnosti prebivalstva, zaposlitvene razmere, izobraževalne razmere, oskrbne razmere, storitvene razmere, možnosti za opravljanje prostočasnih dejavnosti, prometne razmere, naravna ogroženost na območju bivanja, naravne razmere na območju bivanja in onesnaženost bivalnega okolja.

Navedene vidike življenjske ravni (imenovali smo jih "vsebine življenjske ravni") smo izmerili s trinajstimi "delnimi indeksi življenjske ravni", izračunanimi na podlagi 108 kazalcev življenjske ravni (podrobnejši opis metode: Krevs, 1998 a,b). S tem smo življenjsko raven predstavili "po delih". Naš končni cilj pa je, da jo predstavimo kot celoto. To smo naredili na dva načina: s skupnim indeksom življenjske ravni in s tipom območne življenjske ravni.

Skupni indeks živlienjske ravni prebivalstva je posebno primeren za prikaz območij, na katerih se izrazito "kopičijo" predvsem ugodne ali predvsem neugodne življenjske razmere.V prvem primeru je vrednost skupnega indeksa visoka, v drugem nizka. Mani pa je metoda uporabna za opis življenjskih razmer na območjih z vrednostmi skupnega indeksa življenjske ravni okoli povprečja. Iz takšnega seštevka namreč ni mogoče razbrati, kateri vidiki življenjske ravni so ugodni oziroma neugodni.

Tipi območne življenjske ravni so opredeljeni na podlagi kombinacii vrednosti delnih indeksov življenjske ravni (ne njihovega skupnega seštevka) oziroma na podlagi ugotovljenih "tipičnih" kombinacij ugodnih in neugodnih življenjskih razmer na obravnavanih območjih. Za območja istega tipa je značilna takšna "tipična kombinacija" ali splet življenjskih razmer. Z drugimi besedami, območja istega tipa imajo z vidika življenjske ravni prebivalstva podobne primerjalne prednosti ali podobne težave. 


\section{Prostorski vzorci razlik v življenjski ravni prebivalstva med obmejnimi območji}

S proučitvijo razlik med obravnavanimi obmejnimi območji z vidika izbranih posameznih kazalcev življenjske ravni prebivalstva želimo ugotoviti značilne, "tipične" prostorske razmestitve ("prostorske vzorce") ugodnih oziroma neugodnih življenjskih razmer.

Proučili smo karte izbranih posameznih kazalcev življenjske ravni, ki predstavljajo različne vidike (vsebine) življenjske ravni: bruto osnovo dohodnine na prebivalca, stanovanjsko površino na stanovalca, delež infrastrukturno opremljenih stanovani (s priključki na električno, kanalizacijsko, vodovodno omrežje in s centralno kurjavo), indeks števila prebivalcev ( $v$ obdobju 1981-1991), indeks staranja prebivalstva, delež prebivalstva z visoko izobrazbo, delež zaposlenih v terciarnih in kvartarnih dejavnostih, število prodajaln, oddaljenost od najbližjega kinematografa, višinski razpon poseljenih območij, delež poplavno ogroženih poseljenih območij, delež poseljenih površin s pogostim pojavljanjem temperaturnega obrata ter delež poseljenih površin z močno ali prekomerno onesnaženim zrakom. Vrednosti kazalcev so bile za prikaz na kartah razdeliene $v$ razrede po kvartilih: $v$ vsakem razredu je bila četrtina vseh krajevnih skupnosti v Sloveniii. Na ta način smo lahko za posamezen kazalec opravili tudi neposredne primerjave posameznih območij s slovenskim povprečjem.

$\checkmark$ grobem ugotavljamo štiri načine prostorske razmestitve življenjskih razmer na obravnavanem obmejnem območju, ki se bolj ali manj medsebojno prepletajo:

1. izrazita razlika med jugozahodnimi (zahodno od Loškega potoka) in preostalimi obmejnimi območii;

2. izrazita razlika med mestnimi oziroma središčnimi ( $v$ nekaterih primerih vključno s sosednjimi suburbaniziranimi območji) in podeželskimi obmejnimi območji;

3. izrazita razlika med ravninskimi (vključno s kotlinskimi in dolinskimi) in hribovitimi obmejnimi območii;

4. druge prostorske razmestitve življenjskih razmer, ki so lahko na primer posledica posebnosti prikazanega pojava, kulturnih razlik, različne zgodovine, ali zgolj različnih možnosti za gospodarski in družbeni razvoj. 
Pretežno na prvi način se prostorsko porazdeljujeta bruto osnova dohodnine na prebivalca in stanovanjska površina na stanovalca, v izrazitejši kombinaciii z drugim načinom pa še delež zaposlenih v terciarnih in kvartarnih dejavnostih. Pretežno na drugi način so razmeščeni delež infrastrukturno opremljenih stanovanj, delež prebivalstva z visoko izobrazbo, prodajalne in oddaljenost od najbližjega kinematografa, $v$ kombinaciji s četrtim načinom še indeks števila prebivalcev in indeks staranja prebivalstva. Reliefna izoblikovanost se najboli odraža $v$ razmestitvi višinskega razpona poseljenih območii, deleža poplavno ogroženih poseljenih območij ter deleža poseljenih površin $\mathrm{s}$ pogostim pojavljanjem temperaturnega obrata, $v$ kombinaciji $z$ drugim načinom še deleža poseljenih površin $z$ močno ali prekomerno onesnaženim zrakom.

\section{Obmejna območja z najbolj in najmanj ugodnimi življenjskimi razmerami}

Skupni indeks in $v$ naslednjem poglavju predstavljena tipologija življenjske ravni prebivalstva predstavljata življenjske razmere na obravnavanih obmejnih območjih kompleksno, z vidika njihovega "součinkovanja". Med različnimi navedenimi načini prostorske razmestitve življenjskih razmer, $v$ prostorski razmestitvi kompleksnih prikazov živlienjske ravni prebivalstva očitno najbolj izstopa drugi način.

Območja z najvišjimi vrednostmi skupnega indeksa življenjske ravni oziroma z najbolj ugodnimi življenjskimi razmerami so $v$ naslednjih središčnih naselijh (Karta 1): Izola, Piran, Portorož, Ilirska Bistrica, Črnomeli, Metlika, jugovzhodno obrobje Novega mesta, Rogaška Slatina, Ormož in Ljutomer. Med navedenimi središči ni Lendave, ki po višini skupnega indeksa življenjske ravni ne dosega niti manjših lokalnih središč, kot so Materija, Podgrad ali Podčetrtek. Območja z najnižjimi vrednostmi skupnega indeksa živlienjiske ravni zajemajo pretežni del podeželskih obmejnih območij. 
Karta 1: Skupni indeks življenjske ravni prebivalstva na obravnavanih obmejnih območjih.

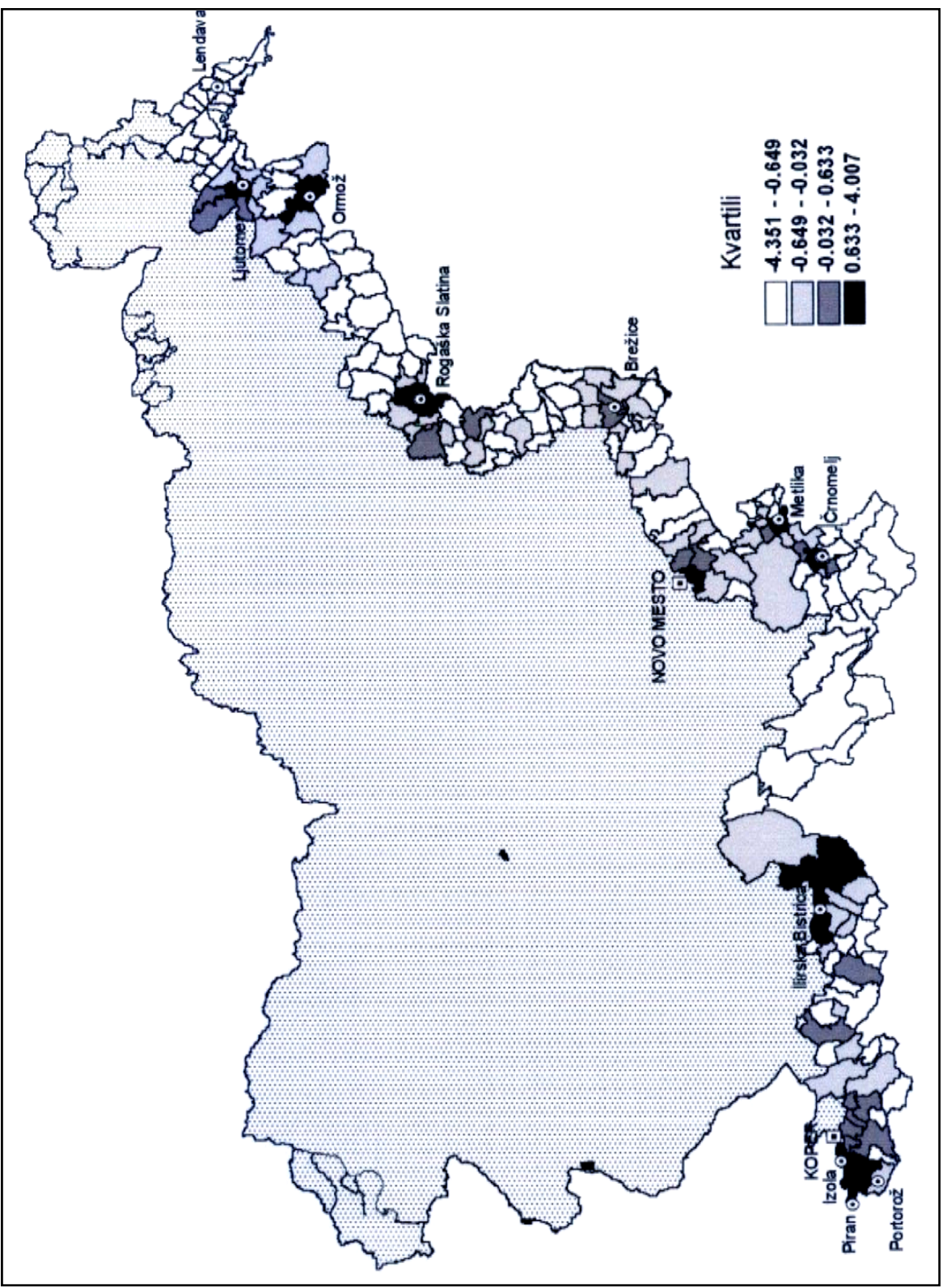




\section{Obmejna območja s podobnimi življenjskimi razmerami}

Predstavljamo preprostejšo izmed tipologii območne življenjske ravni prebivalstva, s štirimi tipi. Menimo, da zadošča za grobo opredelitev območij s sorodnimi kombinacijami življenjskih razmer. Podrobnejšo tipologijo si je mogoče ogledati v omenjeni temeljni raziskavi (Krevs, 1998a). Značilnosti štirih tipov podajamo v Preglednici 1, njihovo razmestitev pa na Karti 2. V "tip 1" so uvrščena območja $v$ središčih, ki imajo nadpovprečne možnosti za prostočasne dejavnosti (slednje vključujejo tudi društva, gostinske in turistične dejavnosti): Piran, Portorož, del Izole, llirska Bistrica, Metlika, Semič, Črnomeli, Brežice, Podčetrtek, Ormož, Ljutomer in Lendava. V "tip 2" so uvrščena območja $\checkmark$ večjih središčih, na katerih lahko nekoliko izstopa onesnaženost bivalnega okolja: pretežni del Izole, del zaledja Izole in Kopra, del Črnomlja, Brežic, jugovzhodno obrobje Novega mesta. V "tip 3" so uvrščena podeželska območja s povprečnimi življenjskimi razmerami (povprečnimi z vidika celotne Slovenije). Praviloma so ta podeželska območja v bližini središč. V "tip 4" so uvrščena podeželska območja s pretežno neugodnimi živlienjskimi razmerami, a s pretežno neonesnaženim bivalnim okoljem. Tudi ta tip območij lahko seže do središč, vendar so zani značilna predvsem večja sklenjena območja, ki so odmaknjena od središč.

Preglednica 1: Opis štirih tipov lokalne življenjske ravni.

\begin{tabular}{|l|l|}
\cline { 2 - 2 } \multicolumn{1}{c|}{} & Opisi tipov \\
\hline Tip 1 & $\begin{array}{l}\text { zelo ugodne razmere z vidika prostočasnih dejavnosti, ugodne razmere z } \\
\text { vidika storitev, oskrbe, izobraževanja, zaposlitve, neugodne razmere z vidika } \\
\text { premoženja kmečkih gospodarstev }\end{array}$ \\
\hline Tip 2 & $\begin{array}{l}\text { ugodne razmere z vidika izobraževanja, stanovani, zaposlitve, prometa, } \\
\text { oskrbe, storitev, neugodne razmere z vidika onesnaženosti bivalnega okolja }\end{array}$ \\
\hline Tip 3 & vrednosti vseh indeksov v okviru povprečnih \\
\hline Tip 4 & $\begin{array}{l}\text { ugodne razmere z vidika onesnaženosti bivalnega okolja, neugodne razmere z } \\
\text { vidika stanovanj, izobraževanja, oskrbe, prometa, storitev, zaposlitve, } \\
\text { prostočasnih dejavnosti }\end{array}$ \\
\hline
\end{tabular}

V opisih tipov niso navedene razmere, ki so blizu povprečnih za celotno Slovenijo. Vir: Krevs, 1998a, 183. 
Karta 2: Štirje tipi živlienjske ravni prebivalstva na obravnavanih obmejnih območjih.

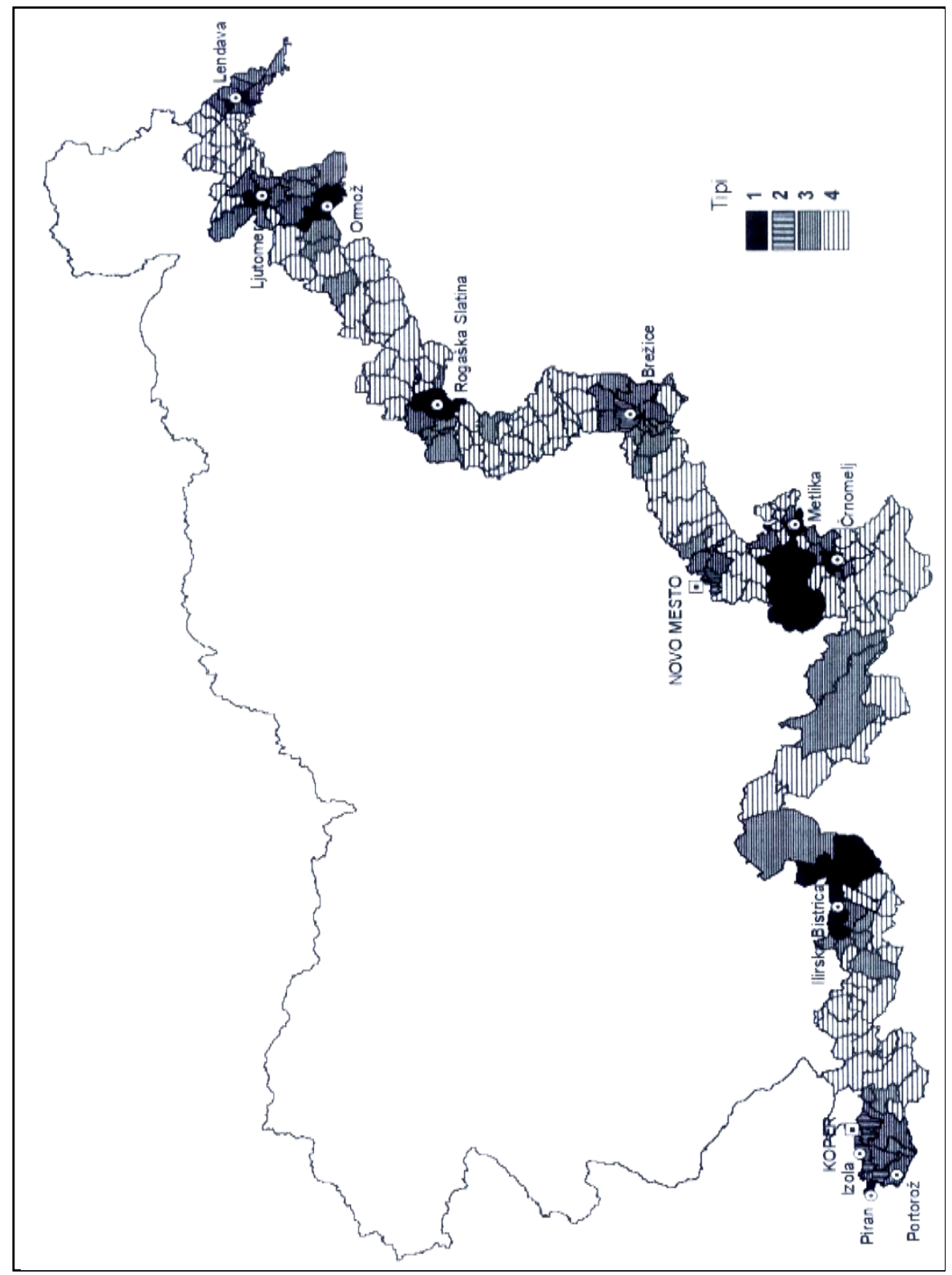




\section{Sklep}

Obmejnost ima še vedno velikokrat slabšalni pomen, ki izpostavlja robnost, perifernost, odmaknjenost od središč in razvoja. $V$ prispevku pokažemo, da za slovenska obmejna območja ob meji s Hrvaško tak stereotip pregrobo poenostavlja pestro resničnost. Na obravnavanem obmejnem območju namreč lahko najdemo zelo različne življenjske razmere prebivalstva, od zelo neugodnih do zelo ugodnih. Podobno, kot tudi na območjih znotraj Slovenije. Nikakor ne poskušamo povsem zanikati pomena obmejnosti za življenjske razmere tamkajšnjega prebivalstva. Vendarle pa menimo, da danes na slednje na splošno boli, kot obmejnost, vplivajo na primer urbaniziranost, bližina (gospodarsko razvitih) središč, razvitost širšega območja (regije), seveda pa tudi razmere na drugi strani meje (slednjih sicer $v$ analizah nismo upoštevali).

Za del obravnavanih obmejnih območij zgoraj omenjeni stereotip vendarle $\checkmark$ veliki meri velja. Za opredelitev "problematičnih območij" s skrajno neugodnimi živlienjskimi razmerami in obenem tudi neugodnimi razvojnimi izgledi poleg skrajno nizkih vrednosti skupnega indeksa življenjske ravni oziroma pripadnosti tipu 4 upoštevamo še kazalca skrajno neugodnih demografskih razmer (visok indeks staranja, nizek indeks števila prebivalstva). Med takšna "problematična območja" sodijo velik del zaledja Koprskega Primorja z Brikini, območja ob zgornjem toku Kolpe, velik del Kozjanskega, Haloze ter nekatera manjša območja v vzhodnih Slovenskih goricah, Pomurju (okoli Lendave) in severni rob Bele Krajine (severno od Metlike).

\section{Viri in literatura}

Analiza dostopnosti naselij do cestne in železniške mreže $\vee$ R Sloveniji, 1996. Ministrstvo za okolje in prostor, Urad za prostorsko planiranje RS; izvajalec Omegaconsult d.o.o., Ljubljana.

Cegnar T., (urednica), 1996: Climate of Slovenia. Hydrometeorological Institute of Slovenia, Liubliana.

DMR 100, digitalni model reliefa Slovenije, po celicah 100x100 metrov. Geodetska uprava RS, Ljubljana; popravki Geografski inštitut ZRC SAZU, Ljubljana, stanje 1992. 
Integrated Resource Planning - Sociotechnical and Policy Aspects, 1995 (vodja projekta dr. Miha Tomšič). Zbirka podatkov in rezultatov analiz. Inštitut Jožef Stefan, Center za energetsko učinkovitost. Ljubljana.

Drewnowski J., Scott, W. 1966: The level of living index. United Nations Research Institute for Social Development, Report No. 4, Geneve, str. 44-45. Povzeto po Novak, 1996.

Knox P.L. 1975: Social well-being: a spatial perspective. Theory and practice in geography. Oxford University Press.

Krevs M. 1996: Geografski vidiki življenjske ravni prebivalstva. Spodnje Podravje s Prlekijo. Možnosti regionalnega in prostorskega razvoja. 17. zborovanje slovenskih geografov, 23.-26.10.1996, Ptuj. Zveza geografskih društev Slovenije, Ljubliana; str. 335-349.

Krevs M. 1998a: Geografski vidiki življenjske ravni prebivalstva v Sloveniji. Doktorska disertacija, Oddelek za geografijo, Filozofska fakulteta $\vee$ Ljubliani.

Krevs M. 1998b: Računski postopki v raziskavi "Geografski vidiki živlienjske ravni prebivalstva $\vee$ Sloveniji". Raziskovalno poročilo. Oddelek za geografijo, Filozofska fakulteta, Univerza v Ljubljani, Ljubljana; 21 str.

Krevs M. 1998c: Digitalna zbirka podatkov za doktorsko raziskavo " Geografski vidiki življenjske ravni prebivalstva v Sloveniij". Oddelek za geografijo, Filozofska fakulteta, Liubliana.

Krevs M. 1999: Glavne razlike v življenjski ravni med slovenskimi mestnimi, obmestnimi in podeželskimi območji. Dela 14: Razvojne možnosti Slovenije. Bodočnost mest. Oddelek za geografiijo, Filozofska fakulteta, Ljubljana; str. 151-162.

Meje krajevnih skupnosti $\vee$ Sloveniii, stanje 1994. Računalniški zapis. Geodetska uprava RS, Ljubljana.

Novak M. 1996: Konceptualna vprašanja proučevanja kakovosti življenja. V: Svetlik, I. (urednik), Kakovost živlienja v Sloveniji. Fakulteta za družbene vede, Ljubliana; str. 7-24.

Okrogla miza "Pomembna vprašanja življenjske ravni z vidika kakovosti živlienja" (več avtorjev), 1991: Ekonomska revija 5, letnik 42 (10/1991). Ekonomska fakulteta $\vee$ Ljubliani, Zveza ekonomistov Slovenije, Ljubliana; str. 307-336.

Podatki o dohodnini za leto 1993 po krajevnih skupnostih v digitalni obliki. Statistični urad RS, Ljubljana. 
Popis prebivalstva in gospodinjstev 1981: podatki po krajevnih skupnostih $v$ digitalni obliki. Statistični urad RS, Ljubljana.

Popis prebivalstva in gospodinjstev 1991: podatki po krajevnih skupnostih $v$ digitalni obliki. Statistični urad RS, Ljubliana.

Popit, I. 1995: S kakšnimi avtomobili se vozimo. Delo 10.8.1995, str. 4.

Poslovni register ( $v$ digitalni obliki), stanje junij 1996. Statistični urad RS, Ljubljana.

Špes, M. (vodja projekta, več avtorjev) 1995: digitalni podatki in karte za vrednotenje ranlijvosti prostora v Sloveniji. Inštitut za geografijo, Liubliana.

Turistične zmogliivosti (digitalni podatki po slovenskih občinah), 1996. Statistični urad RS, Ljubljana.

Vuics, T. 1994: Change in political system - and life quality in Hungary. V: Proceedings of Regional Conference of International Geographical Union in Praha, august 1994. Faculty of Science, Charles University Albertina lcome (CD-ROM).

\section{LEVEL OF LIVING OF THE POPULATION ON THE SLOVENIAN SIDE OF THE BORDER WITH CROATIA}

\section{Summary}

Border areas on the Slovenian side of the border with Croatia are physicalgeographicaly and social-geographicaly very heterogeneous. Therefore, these areas differ substantialy from the point of view of the living conditions of the population. The main purpose of the article is to present these differences in a complex way, based on a complex approach to measuring the level of living of the population.

Thirteen aspects of level of living are measured using complex indices: property and income of population, property of farms, residences, population, employment, education, supply, services, conditions for leisure activities, personal transport accessibility, natural threats to residential areas, physicalgeographical characteristics of residential areas, and pollution of residential areas. Two methods are used to make a complex information from these partial indices of level of living, aggregation to produce aggregated index of level of living, and classification to find out areas with similar combinations of 
the values of the partial indices of level of living (areas of the same type of level of living).

Study of the differences between areas from the point of view of the individual living conditions of the population shows four main spatial patterns, which are more or less combined in reality:

1. distinctive differences between the southwestern part of the studied border areas, and the rest of the studied areas;

2. distinctive differences between centers (mostly urban areas, in some cases associated with neighbouring suburban areas) and rural areas;

3. distinctive differences between areas with prevailing flat land (including basins and wide valleys) and the predominantly hilly areas;

4. other spatial patterns, resulting from special characteristics of the studied phenomenon, cultural, historical differences, or differences in the conditions for economic and social development.

In the spatial patterns of the two complex methods of presenting level of living (aggregated index and classification, Map 1 and Map 2), the second "type" of the mentioned patterns is predominant, with some exceptions.

The areas with the worst living conditions are searched among the areas with very low values of the aggregated index, the fourth type in the classification of level of living of the population (showing the rural areas with very unfafourable living conditions, but unpolluted environment), and unfavourable demographic circumstances (indicated by index of the size of the population in the period 1981-1991, and the ratio of the population of the age above 65 to the population of the age below 15). 


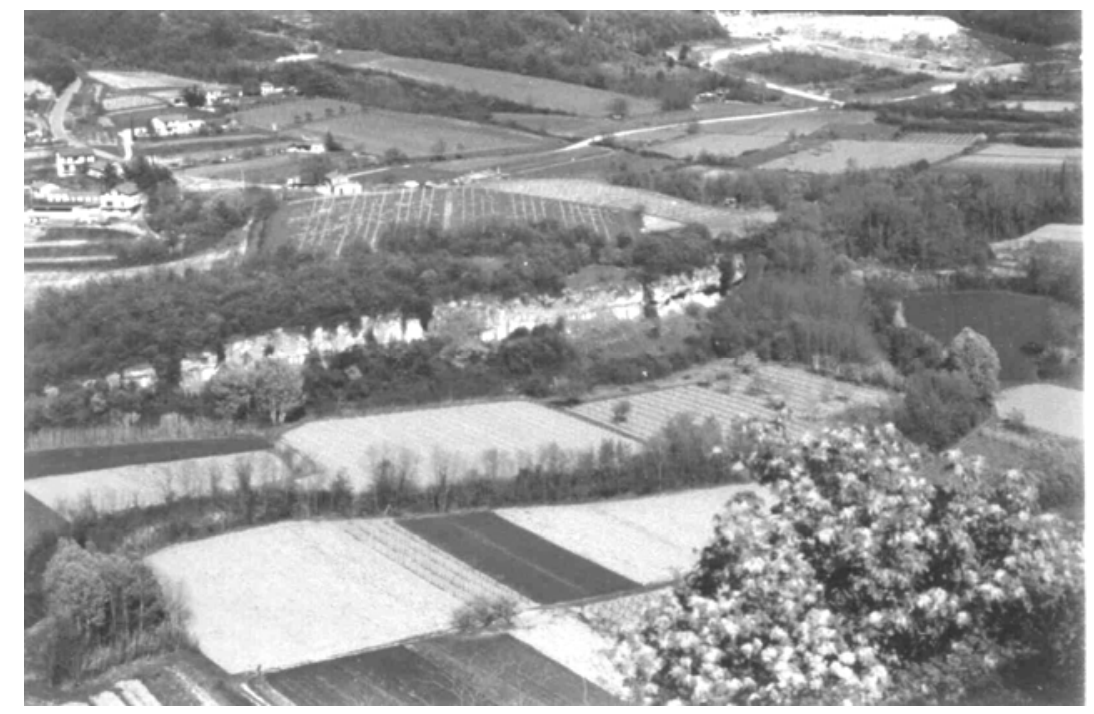

SI. 2: Obalni pas Slovenske Istre sestavljajo polotoki, ki se ponekod zaključujejo $\mathrm{s}$ strmimi klifi in obalne ravnice $v$ notranjosti zalivov. Ravnice so nastale $z$ nasipavanjem vodotokov, ki pritečejo s flišnega zaledja. Največja je ob spodnji Dragonji, kjer so ob izlivu reke $v$ morje uredili soline, med solinami in vasjo Dragonja (na sliki) pa so kvalitetne kmetijske površine. (foto: D.Ogrin) 